\title{
Test Plan to Update SRS HLW Tank Material Properties Database by Determining Synergistic Effects of Dynamic Strain Aging and Stress Corrosion Cracking
} (U)

\author{
K. H. Subramanian \\ Savannah River Technology Center \\ Strategic Materials Technology Department \\ Materials Technology Section
}

Publication Date: December 2001

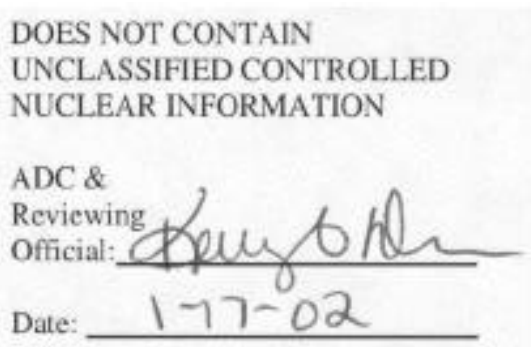

Patent Status

This internal management report is being transmitted without DOE patent clearance, and no further dissemination or publication shall be made of the report without prior approval of the DOE-SR patent counsel.

\section{Westinghouse Savannah River Company}

Savannah River Site

Aiken, SC 29808

This document was prepared in connection with work done under Contract No. DE-AC09-96SR18500 with the U. S. Department of Energy 
This document was prepared in conjunction with work accomplished under Contract No. DE-AC09-96SR18500 with the U. S. Department of Energy.

\section{DISCLAIMER}

This report was prepared as an account of work sponsored by an agency of the United States Government. Neither the United States Government nor any agency thereof, nor any of their employees, makes any warranty, express or implied, or assumes any legal liability or responsibility for the accuracy, completeness, or usefulness of any information, apparatus, product or process disclosed, or represents that its use would not infringe privately owned rights. Reference herein to any specific commercial product, process or service by trade name, trademark, manufacturer, or otherwise does not necessarily constitute or imply its endorsement, recommendation, or favoring by the United States Government or any agency thereof. The views and opinions of authors expressed herein do not necessarily state or reflect those of the United States Government or any agency thereof.

This report has been reproduced directly from the best available copy.

Available for sale to the public, in paper, from: U.S. Department of Commerce, National Technical Information Service, 5285 Port Royal Road, Springfield, VA 22161, phone: (800) 553-6847, fax: (703) 605-6900

email: orders@ ntis.fedworld.gov

online ordering: http://www.ntis.gov/support/index.html

Available electronically at http://www.osti.gov/bridge

Available for a processing fee to U.S. Department of Energy and its contractors, in paper, from: U.S. Department of Energy, Office of Scientific and Technical Information, P.O. Box 62, Oak Ridge, TN 37831-0062,

phone: (865)576-8401,

fax: (865)576-5728

email: $\underline{\text { reports@ adonis.osti.gov }}$ 
WSRC-TR-2001-00590

DOCUMENT: $\quad$ WSRC-TR-2001-00590

TITLE:

Test Plan to Update SRS HLW Tank Material Properties Database by Determining Synergistic Effects of Dynamic Strain Aging and Stress Corrosion Cracking (U)

APPROVALS

Vnatturi her:

Date:

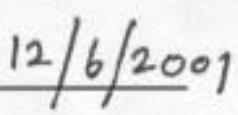

K. H. Subramanian, Author

Materials Performance and Corrosion Technology Group

Materials Technology Section

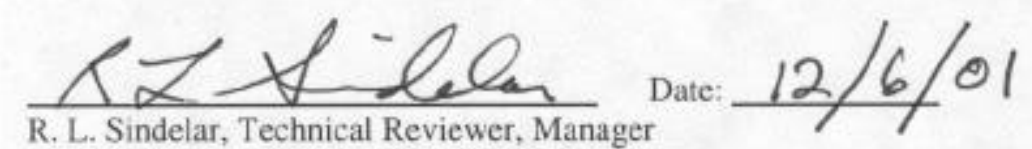

R. L. Sindelar, Technical Reviewer, Manager

Materials Applications \& Process Technology Group

Materials Technology Section

Dree of Wees Date: $12 / 6 / 01$

B. J. Wiersma, Tank Life Management Program

Materials Performance and Corrosion Technology Group

Materials Technology Section

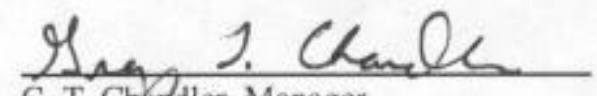

Date:

$12 / 6 / 01$

G. T. Chandler, Manager

Materials Performance \& Corrosion Technology Group

Materials Technology Section

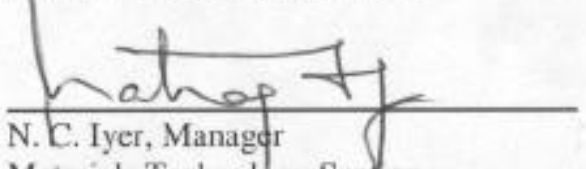

Date: $1 / 10 / 02$

Materials Technology Section

Savannah River Technology Center 
WSRC-TR-2001-00590

\section{INTRODUCTION}

The structural integrity of High Level Waste (HLW) tanks is defined by the demonstrated confinement of the waste by the tank structure under design basis conditions. The validity of a structural integrity assessment depends on the availability of a reliable mechanical and corrosion property database and require application of contemporary fracture analyses. In addition, accurate characterizations of the active degradation/corrosion mechanisms are necessary to ensure structural integrity throughout the intended life of the HLW tanks. A complete mechanical and corrosion property database will provide the foundation for a robust structural integrity assessment. The focus of the proposed work was to quantify the degradation mechanisms and the effect of dynamic strain aging (DSA) on the mechanical properties and degradation mechanisms, particularly stress corrosion cracking(SCC), in low carbon steel that is reflective of tank material. A comprehensive test plan is presented here to develop a mechanical and corrosion properties database to develop a fundamental understanding of the synergistic effects of DSA and SCC due to high temperature service of the HLW tanks.

HLW tanks are susceptible to various degradation mechanisms. From a corrosion standpoint, pitting and stresscorrosion cracking have been found to be potential active mechanisms. Chemistry control maintained on waste introduced into the tanks at SRS prevents the initiation of pitting and stress corrosion cracking outside the residual stress field. These have been extensively studied although some gaps exist in the database and specific environmental conditions most conducive to degradation mechanisms.

Degradation of the low carbon steel due to the high temperatures experienced during waste filling cycles needs to be addressed. The role of dynamic strain aging (DSA) in the temperature ranges experienced by the tanks during waste filling cycles history needs to be understood. The quantification of the possible synergistic effects of dynamic strain aging and stress corrosion cracking on low carbon steel due to service in high temperature will allow for accurate fill limit calculations and structural integrity assessments.

\section{BACKGROUND}

\subsection{Stress Corrosion Cracking}

Cracking of structural components exposed to corrosive environments may occur under stresses that are less than the yield stress of the material. The cracking mechanism under these conditions is termed stress corrosion cracking (SCC). The SCC crack growth rate generally varies with the stress intensity parameter $\left(\mathrm{K}_{\mathrm{I}}\right)$ in the manner shown in Figure 1. In region A, crack growth is strongly related to stress intensity but drops very rapidly, nominally to zero. Extrapolation to zero crack growth provides the value $\mathrm{K}_{\mathrm{Iscc}}$., the stress intensity factor above which $\mathrm{SCC}$ will initiate and grow for the specified condition (material, environment, exposure time, etc.) under predominantly plane strain conditions. This parameter is a material property for a specific environment/material system. 
WSRC-TR-2001-00590

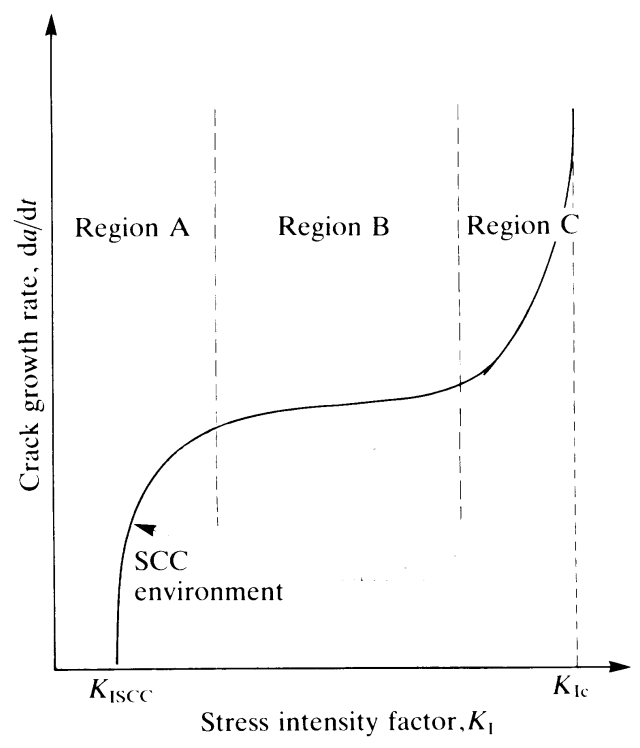

Figure 1: Testing of susceptibility to SCC by crack growth rate measurements.

Variables that affect $\mathrm{K}_{\mathrm{Iscc}}$. include thickness, fabrication and heat treatment, and orientation of the hot rolled steel. ${ }^{2}$ Therefore, knowledge of the actual plate thickness, the material fabrication processes (cold-work, hot-forming, etc.), and the procedures for construction would facilitate use of appropriate test data for application to fracture analyses.

\subsection{SCC of SRS Type I and II HLW Tanks}

Laboratory tests were performed at SRS to determine the effect of the waste composition on stress corrosion crack growth in A285 material. ${ }^{3}$ Type I and Type II HLW tanks were fabricated with ASTM A285 Grade B steel. Modified wedge opening load (WOL) specimens were utilized to determine $\mathrm{K}_{\mathrm{Iscc}}$. Material was machined into a 0.75" thick WOL specimen with side grooves to ensure Mode I crack growth and minimize crack tunneling. The specimens were fatigue pre-cracked and pre-stressed to an apparent stress intensity $\left(\mathrm{K}_{\mathrm{I}}\right)$ of $45 \mathrm{ksi}$ in. Due to the large plasticity of the mild steel, the load required to achieve an actual stress intensity of $45 \mathrm{ksi} V$ in could not be met, and the corresponding crack opening displacement was used to calculate the apparent applied stress intensity.

The pre-stressed specimens were immersed in 5 molar (M) sodium nitrate solutions that contained various amounts of sodium hydroxide ( 0 to $1.5 \mathrm{M}$ ) and sodium nitrite $(0$ to $3 \mathrm{M})$. The test temperature was $95^{\circ} \mathrm{C}$. The stress intensity, $\mathrm{K}_{\mathrm{I}}$, a parameter that characterizes the state of stress in the crack tip region, decreases with crack length for a WOL specimen. Therefore, the threshold stress intensity, $\mathrm{K}_{\mathrm{Iscc}}$ (the minimum stress intensity for stress corrosion cracking under plane-strain conditions), is the corresponding $\mathrm{K}_{\mathrm{I}}$ value at crack arrest. In addition, $\mathrm{K}_{\mathrm{Iscc}}$ was observed to be relatively independent of the bulk solution chemistry, indicating that crack tip chemistry is independent of bulk chemistry. The average $\mathrm{K}_{\mathrm{Iscc}}$ was $28.5 \mathrm{ksi}$ in.

The threshold data revealed the potential for SCC. Therefore, it became necessary to predict crack extension based on crack growth rate data, in case the stress intensity due to flaws exceeded $\mathrm{K}_{\mathrm{Iscc}}$. Over region $\mathrm{B}$ in Figure 1, cracks grow at a constant rate that is relatively independent of stress intensity. It is believed that the growth rate is related to the corrosion processes that are occurring at the crack tip. Crack length as a function of time was also measured during the WOL tests. The growth rate was also observed to be independent of the bulk solution chemistry. The average crack growth rate was 1.25 inches per year, corresponding to region B of the SCC susceptibility curve.

In region $\mathrm{C}$ of Figure 1 the stresses are very high, and the inter-atomic bonds break before any significant corrosion reactions can occur. The crack growth rate accelerates rapidly as the value for $\mathrm{K}_{\mathrm{I}}$ approaches $\mathrm{K}_{\mathrm{Ic}}$ for the material.

Two possible mechanisms of stress corrosion cracking in High Level Waste Tanks through information available from Tanks 15 and 16: (1) liquid space SCC, and (2) vapor space SCC. Tank 16 is a retired Type II tank that is 
considered the bounding case because it represents the worst case of leakage from a high level waste tank. Tank 15 is a Type II waste tank in which a suspected $15 \mathrm{in}$. crack has developed above the middle girth weld. The region was in the vapor space of the tank throughout the period of crack growth. The vapor space crack revealed in Tank 15 is a new phenomenon not previously expected in the tank structural integrity program, and is currently being investigated through a test program.

\subsection{Strain Aging/Dynamic Strain Aging (DSA)}

Strain aging is the aging of low carbon steel with plastic deformation. The cause of strain aging is the segregration of the interstitial solute atoms (i. e. carbon and nitrogen) to the strain fields around dislocations in the lattice. Within the dislocation strain fields, nitrogen and carbon atoms can migrate from nitride or carbide particles to dislocation sites, thus pinning the dislocations. As a result, the subsequent plastic deformation requires a higher stress.

Generally, strain aging causes increased hardness, yield and tensile strength, reduced ductility, and increased notchimpact transition temperature. In addition, strain aging can lead to brittle crack growth in an otherwise ductile steel. The most common measure of strain aging is the increase in yield strength. ${ }^{4}$ Much of this section is reproduced from Reference 4. Figure 2 shows the stress strain-curve for annealed or normalized low-carbon steel strained to point ' $A$ ', unloaded, and then immediately restrained (curve 'a') and after aging (curve 'b'). It is seen that strain aging has created a higher yield stress indicated by $\Delta \mathrm{Y}$.

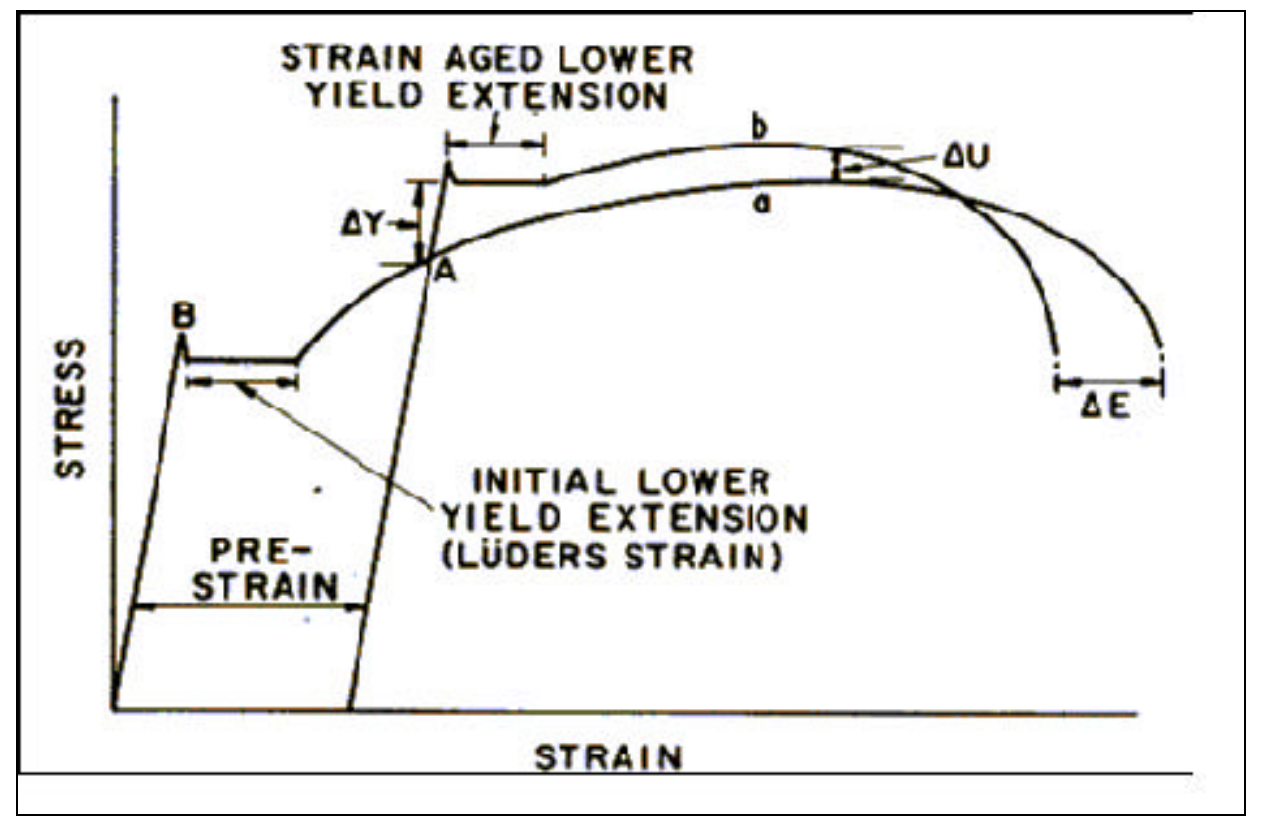

Figure 2: Elevated Yield Point in Normalized Low-Carbon Steel due to Strain Aging.

The rate at which strain aging occurs depends upon the concentration and the rate of diffusion of carbon and nitrogen at the aging temperature. As the aging temperature increases, the rate of aging increases sharply. Table 1 gives the aging times at several temperatures to produce approximately equal aging effects in low carbon steel, as reproduced from Reference 4, estimated for a low-carbon steel. 
WSRC-TR-2001-00590

Table 1: Aging Times at Select Temperatures that Produce Equivalent Aging Effects.

\begin{tabular}{c|c|c|c|c}
\hline $0^{\circ} \mathrm{C}$ & $21^{\circ} \mathrm{C}$ & $100^{\circ} \mathrm{C}$ & $120^{\circ} \mathrm{C}$ & $150^{\circ} \mathrm{C}$ \\
\hline 1 year & 6 months & 4 hours & 1 hour & 10 min. \\
6 months & 3 months & 2 hours & 30 min. & 5 min. \\
3 months & 6 weeks & 1 hour & 15 min & 2.5 min \\
1 month & 2 weeks & 20 min. & 5 min. & \\
1 week & 4 days & 5 min. & & \\
3 days & 36 hours & 2 min. & & \\
\hline
\end{tabular}

If a specimen is strained at a temperature at which the carbon and nitrogen can diffuse to dislocations during the straining, then strain aging will occur. This phenomenon is known as dynamic strain aging (DSA) and is associated with blue brittleness of steel. It is characterized by sharply serrated stress-strain curves, as shown in Figure 3. It is seen that dynamic strain aging is a more effective and economical method of strain aging than the conventional straining at room temperature then aging.

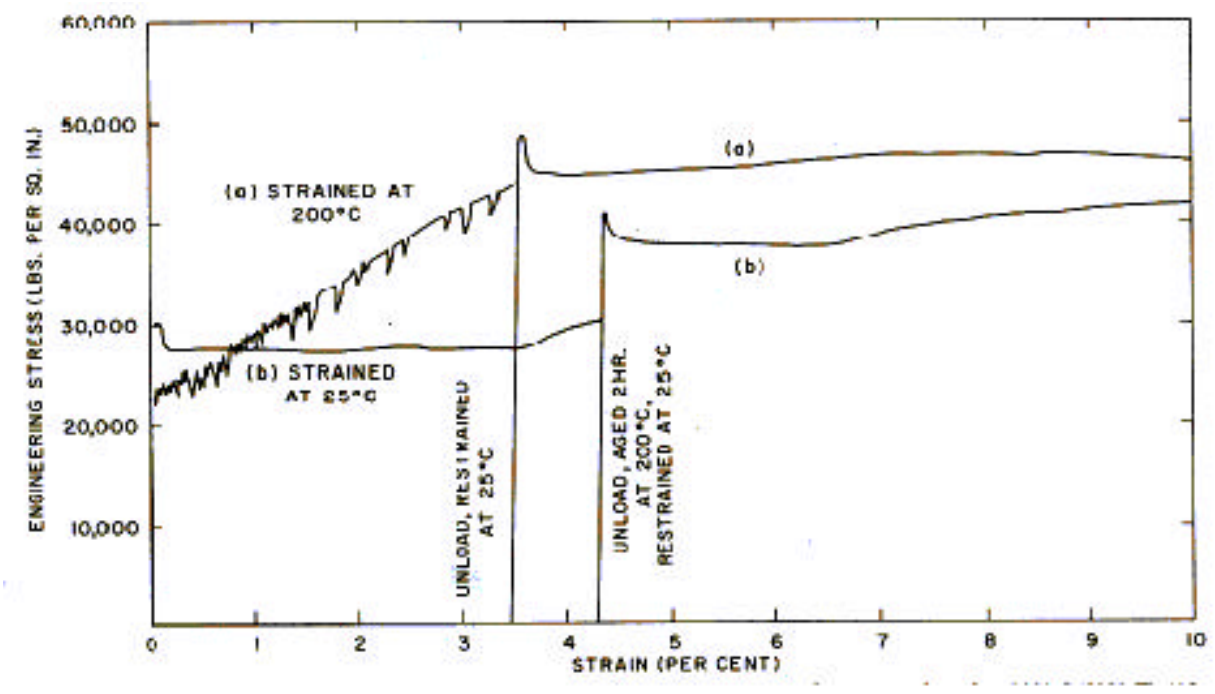

Figure 3: Stress-Strain Comparison of a Dynamically Strain Aged and Strain Aged Low Carbon Steel.

The interaction between dynamic strain aging and stress corrosion cracking has been of recent interest. Chu has reported that for medium carbon low alloy steels, susceptibility to SCC in aqueous solution was very low except near the "blue brittleness" temperature. ${ }^{5}$ In addition, a synergistic action between the blue brittleness (caused by dynamic strain aging) and SCC was suggested, resulting in a steep increase in the susceptibility to SCC.

\subsection{Applicability to SRS HLW Tanks}

A review of the service history of the SRS HLW tanks considered factors that may have induced significant degradations. The HLW tanks are made of low-carbon steel that are known to be susceptible to strain aging. The temperature histories indicate that most of the Type I and II tanks were in service as fresh waste receivers, indicating extended high-temperature service that may have induced strain aging. In addition, Type I and II HLW tanks have incurred nitrate stress corrosion cracking around fabrication and repair welds, postulated to have initiated and grown within the first several years of service before the institution of waste chemistry control. The combination of stress corrosion cracks and high temperature service may have the potential of inducing dynamic strain aging. In order to provide an accurate representation of material properties input into a structural integrity assessment, this possibility 
of dynamic strain aging must be accounted for.

\section{TECHNICAL APPROACH}

A mechanical properties test program, as part of the Structural Integrity Program, is in place to develop a reliable and comprehensive fracture toughness and tensile properties database for low carbon steel as a function of the following: (1) temperature, (2) material composition, (3) thickness, and (4) orientation. The scope of this proposed work is to develop mechanical and corrosion testing to quantify the effects of high temperature degradation, specifically DSA, SCC, and pitting. A representative heat of steel will be initially chosen for testing and chemical analyses. Materials will be chosen such that their chemical compositions will span low carbon steel compositions that are seen in HLW tanks across the DOE complex. Mechanical property testing and corrosion testing will be performed on a representative heats of steel. Additional testing needs to be conducted wherein samples are strain aged to reflect the temperature profiles of the HLW tanks. The results may be used to establish the vulnerability of the HLW tank material to the DSA phenomenon and general degradation/corrosion as a function of temperature history.

\subsection{Materials}

The material used for this testing will be heats of steel chosen from the dozen heats of the complete mechanical test program. A relatively high-carbon, high-impurity heat, Heat E400, will be used for the initial testing. The E400 heat is near the upper bound of the heats of the plates comprising the Type I and II waste tanks in terms of carbon and impurity content. The results of the previous testing program have indicated that fracture toughness properties of ASTM A285 steel are dependent on the carbon content as expected. Increased carbon content indicates increased pearlite content, which has been shown to reduce the fracture energy in steels. ${ }^{6}$

\subsection{Test Matrix}

The test program will attempt to indicate an interaction between stress corrosion cracking and dynamic strain aging. Compact tension specimens will be fracture toughness tested in the temperatures ranging from $25^{\circ} \mathrm{C}$ to $325^{\circ} \mathrm{C}$. The compact tension specimen geometry that will be used for fracture toughness testing is shown in Figure 4 . An extra width specimen will be used to allow for back-end constraint restrictions. In addition, the specimens will be $20 \%$ side-grooved to minimize crack tunneling. 


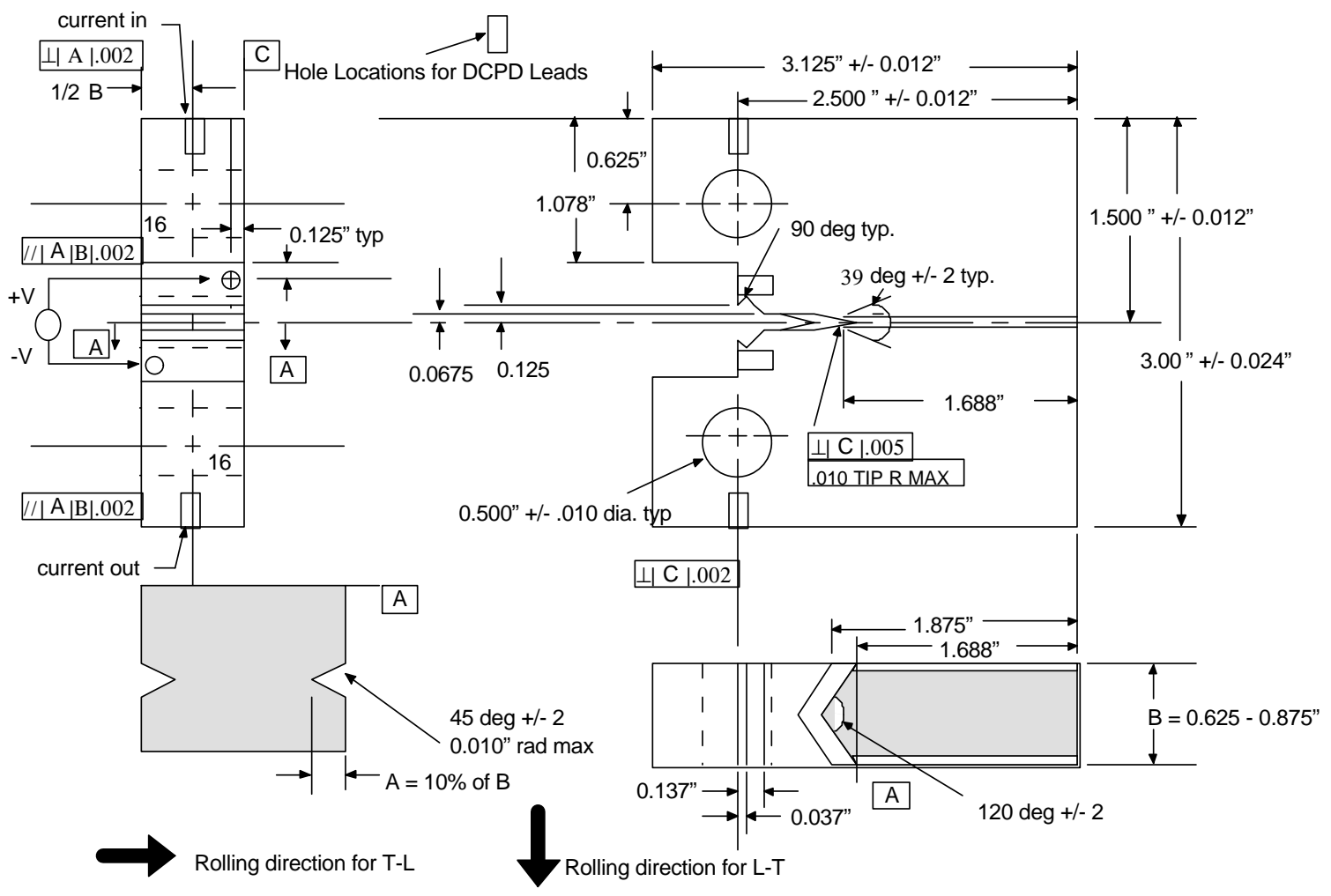

Figure 4: Compact Tension Specimen Design

Slow strain rate fracture toughness testing will be done at temperatures between $25^{\circ} \mathrm{Cand} 325^{\circ} \mathrm{C}$ in 50 -degree increments. A J-R curve will be developed for each sample. The following section discusses the details of the fracture toughness testing.

\subsection{Fracture Toughness Testing}

The standard method for J-integral characterization described in ASTM Standard E1820: "Standard Test Method for Measurement of Fracture Toughness" will be used to develop J-R curves. The specimens will be side-grooved to prevent extensive crack tunneling. The specimens will be fatigue-precracked according to ASTM E1820 specifications. The samples will be tested at ambient room temperature. Figure 5 shows the experiment test setup at Case Western Reserve University (CWRU).

Compact tension specimens $(\mathrm{C}(\mathrm{T})$ 's) will be used to generate the material fracture toughness and crack resistance properties. The crack length will be measured using the "direct current potential drop" (DCPD) method for measuring crack extension. Fracture toughness testing will be done on a MTS hydraulic load frame in a temperature controlled test chamber. Temperature will be measured/monitored using a calibrated temperature probe and controller thermocouple during testing. Load, load-line displacement and crack lengths will be measured for calculation of J- $\Delta$ a curves. Load-line displacement will be measured through the MTS controller to allow for extensive crack opening during testing. 


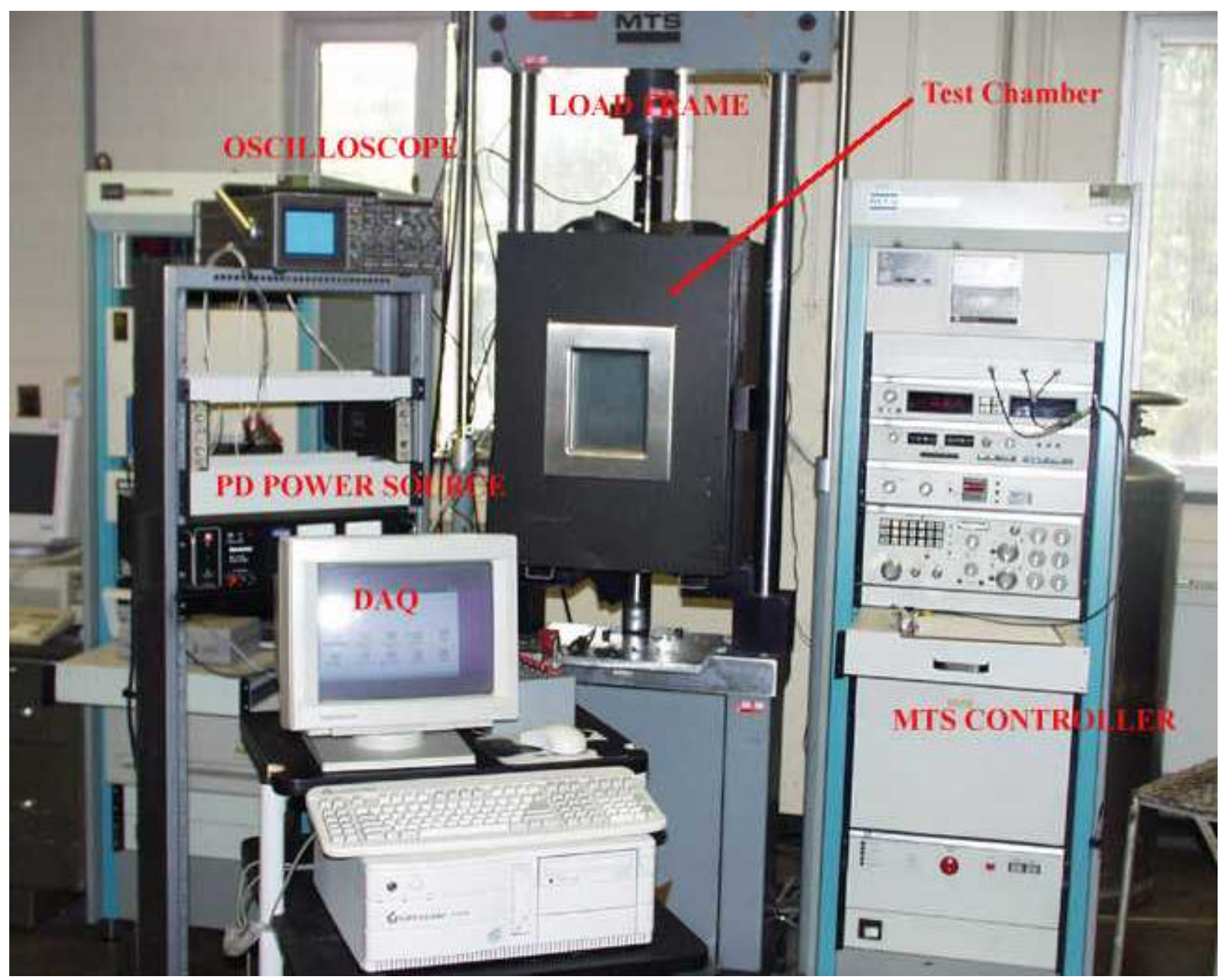

Figure 5: Experimental Setup with Load Frame, Controller, PD Setup, and Test Chamber.

\subsubsection{Measurement of Crack Length (Elastic Unloading Compliance Method)}

The single specimen elastic unloading compliance method is commonly used for J-R curve testing. The equations for estimating crack length $a_{i}$ (crack length a at data point i) in ASTM E1820 are summarized in this subsection:

$$
a_{i} / W=1.000196-4.06319 u+11.242 u^{2}-106.043 u^{3}+464.335 u^{4}-650.677 u^{3}
$$

where $\mathrm{W}$ is the distance from the loading pin hole centerline to the back surface of specimen,

$$
\mathrm{u}=\left(1+\sqrt{\mathrm{B}_{\mathrm{e}} \mathrm{E}^{*} \mathrm{C}_{\mathrm{c}(\mathrm{i})}}\right)^{-1}
$$

$\mathrm{B}_{\mathrm{e}}=\mathrm{B}-\left(\mathrm{B}-\mathrm{B}_{\mathrm{N}}\right)^{2} / \mathrm{B}, \mathrm{B}$ is the thickness of the specimen (for standard specimens, $\mathrm{B}=\mathrm{W} / 2$ ), $\mathrm{B}_{\mathrm{N}}$ is the net thickness excluding the side groove depths $\left(\mathrm{B}_{\mathrm{e}}=\mathrm{B}\right.$ when side grooves are not used $)$,

$E^{*}=E /\left(1-v^{2}\right), E$ is the Young's modulus, $v$ is the Poisson's ratio, and

$\mathrm{C}_{\mathrm{c}(\mathrm{i})}$ is the specimen load-line crack opening elastic compliance on an unloading/reloading sequence $(\Delta \mathrm{v} / \Delta \mathrm{P})$ 
WSRC-TR-2001-00590

corrected for rotation:

$$
C_{c(i)}=\frac{C_{i}}{\left[\frac{H^{*}}{R} \sin \theta_{i}-\cos \theta_{i}\right]\left[\frac{D}{R} \sin \theta_{i}-\cos \theta_{i}\right]}
$$

where:

$\mathrm{C}_{\mathrm{i}}$ is the measured specimen elastic compliance at the load-line $(\Delta \mathrm{v} / \Delta \mathrm{P})$,

$\Delta \mathrm{v}$ is the displacement at the load-line

$\Delta \mathrm{P}$ is the change in load as a function of $\Delta \mathrm{v}$

$\mathrm{H}^{*}$ is the initial half-span of the load points (center of the pin holes),

$\mathrm{R}$ is the radius of rotation of the crack centerline, $(\mathrm{W}+\mathrm{a}) / 2$,

a is the updated crack length,

$\mathrm{D}$ is one half of the initial distance between the displacement measurement points,

$\theta$ is the angle of rotation of a rigid body element about the unbroken midsection line, or

$$
\theta=\sin ^{-1}\left[\frac{\left(\frac{d_{m}}{2}+D\right)}{\sqrt{D^{2}+R^{2}}}\right]-\tan ^{-1} \frac{D}{R}
$$

and $\mathrm{d}_{\mathrm{m}}$ is the total measured load-line displacement.

\subsubsection{Direct Current Potential Drop}

Crack lengths were also measured using the Direct Current Potential Drop Method (DCPD). The specimen was instrumented so that the current would enter the top of the compact tension specimen and exit from the bottom. The output voltage was measured across the crack opening on the load line of the specimen, as shown in Figure 1. As the crack grew, the resistance of the specimen increased due to the reduction of the un-cracked ligament. In the case of constant current, the increased resistance to current flow resulted in an increase in the measured voltage across the crack according to Ohm's law. The DCPD results were corroborated post-test with optical crack length measurements of the fatigue pre-crack and total crack length after testing. The detailed description of DCPD can be found in ASTM E647-95a, "Standard Test Method for Measurement of Fatigue Crack Growth Rates."

\subsubsection{Calculation of J-integral}

The calculation of $\mathbf{J}$ is based on ASTM E1820-99 is summarized here. The J-integral is assumed to be composed of an elastic component $\left(\mathrm{J}_{\mathrm{e} 1}\right)$ and a plastic component $\left(\mathrm{J}_{\mathrm{p}}\right)$ :

$$
\mathrm{J}=\mathrm{J}_{\mathrm{el}}+\mathrm{J}_{\mathrm{pl}}
$$

The $\mathrm{J}$ values can be estimated at any point $\left(\mathrm{P}_{\mathrm{i}}, \mathrm{v}_{\mathrm{i}}\right)$ on the load $(\mathrm{P})$ versus load-line displacement $(\mathrm{v})$ record. The subscript (i or $\mathrm{i}-1$, etc.) represents the points where data were taken.

\subsubsection{Elastic Component of $J$}

The elastic component of $\mathrm{J}$ is converted from the stress intensity factor $(\mathrm{K})$ under plane strain condition: 


$$
\mathrm{J}_{\mathrm{el}(\mathrm{i})}=\frac{1-\mathrm{V}^{2}}{\mathrm{E}} \mathrm{K}_{(\mathrm{i})}^{2}=\frac{1-\mathrm{V}^{2}}{\mathrm{E}}\left[\frac{\mathrm{P}_{\mathrm{i}}}{\sqrt{\mathrm{B} \mathrm{B} \mathrm{W}}} f\left(\frac{\mathrm{a}_{\mathrm{i}}}{\mathrm{W}}\right)\right]^{2}
$$

where

$$
f(x)=\frac{(2+x)\left(0.886+4.64 x-13.32 \quad x^{2}+14.72 \quad x^{3}-5.6 x^{4}\right.}{(1-x)^{3 / 2}} .
$$

\subsubsection{Plastic Component of $J$}

The incremental formula for computing the plastic component of $\mathrm{J}$ is

$$
\mathrm{J}_{\mathrm{pl}(\mathrm{i})}=\left[\mathrm{J}_{\mathrm{pl}(\mathrm{i}-1)}+\frac{\eta_{(\mathrm{i}-1)}}{\mathrm{b}_{(\mathrm{i}-1)}} \frac{\mathrm{A}_{\mathrm{pl}(\mathrm{i})}-\mathrm{A}_{\mathrm{pl}(\mathrm{i}-1)}}{\mathrm{B}_{\mathrm{N}}}\right] \times\left[1-\gamma_{(\mathrm{i}-1)} \frac{\mathrm{a}_{\mathrm{i}}-\mathrm{a}_{(\mathrm{i}-1)}}{\mathrm{b}_{(\mathrm{i}-1)}}\right]
$$

where

$$
\begin{aligned}
& \eta_{(\mathrm{i}-1)}=2.0+0.552 \quad \mathrm{~b}_{(\mathrm{i}-1)} / \mathrm{W} \text {, } \\
& \gamma_{(\mathrm{i}-1)}=1.0+0.76 \quad \mathrm{~b}_{(\mathrm{i}-1)} / \mathrm{W},
\end{aligned}
$$

and $b_{i}$ is the uncracked ligament size.

The increment of plastic area under the load versus plastic load-line displacement curve between the lines of constant displacements at data points (i-1) and (i) is

$$
A_{p l(i)}-A_{p l(i-1)}=\frac{1}{2}\left[P_{(i)}+P_{(i-1)}\right]\left[v_{p l(i)}-v_{p l(i-1)}\right]
$$

where

$$
\mathrm{v}_{\mathrm{pl}(\mathrm{i})}=\mathrm{v}_{\mathrm{i}}-\left(\mathrm{P}_{\mathrm{i}} \mathrm{C}_{\mathrm{LL}(\mathrm{i})}\right) \text {, }
$$

and $\mathrm{C}_{\mathrm{LL}(\mathrm{i})}$ is the compliance. Note that $\mathrm{C}_{\mathrm{LL}(\mathrm{i})}$ shall be replaced by $\mathrm{C}_{\mathrm{c}(\mathrm{i})}$ when the rotation of the specimen becomes significant (Section A2.4.2.2 of ASTM E1820-99).

\section{STRESS CORROSION CRACKING TESTING}

The Wedge Opening Loaded (WOL) specimen design will be used to determine stress corrosion cracking behvaior. The sample will be loaded using an instrumented test bolt. The instrumented test bolt is equipped to measure compression at the bolt tip against the tup in the WOL specimen. Data will be logged using a DL100 Portable Analog Datalogger (by Interface Instrument Corp.) and will periodically be downloaded using ProComm communications software.

The direct load drop will be measured and the crack length calculated using compliance relationships for compact tension specimens from Reference 1. ${ }^{7}$ The Non-dimensional load-line compliance solution for a through-thickness crack in a flat plate is shown in Equation 1, with the component relationships shown in Equations 2-4.

\section{Equation 1: Non-Dimensional Load-Line Compliance for Through Thickness Cracks in Flat Plates}

$$
Z_{L L}=\frac{\Delta B_{e} E^{\prime}}{P}=\left(\frac{1+\frac{a}{w}}{1-\frac{a}{w}}\right)^{2}\left[2.163+12.219\left(\frac{a}{w}\right)-20.065\left(\frac{a}{w}\right)^{2}-0.9925\left(\frac{a}{w}\right)^{3}+20.609\left(\frac{a}{w}\right)^{4}-9.9314\left(\frac{a}{w}\right)^{5}\right]
$$


where: $\quad \mathrm{D}=$ Displacement (shown in Equation 2)

$\mathrm{B}=$ Thickness (effective thickness shown in Equation 3 for side-grooved specimens)

E' = Elastic modulus

$\mathrm{a}=$ Crack length

$\mathrm{w}=$ Width

Equation 2: Total Displacement

$$
\Delta=\Delta_{c}+\Delta_{n c}
$$

where: $\quad \Delta_{\mathrm{c}}=$ Displacement due to crack

$\Delta_{\mathrm{nc}}=$ Displacement in the absence of a crack at a given load.

\section{Equation 3: Effective Thickness where $B_{N}$ is the Net Thickness}

$$
B_{e}=B-\frac{\left(B-B_{N}\right)^{2}}{B}
$$

Equation 4: Elastic Modulus

$$
E^{\prime}=\frac{E}{\left(1-v^{2}\right)}
$$

The load drop measured will be used to calculate a compliance, after which the crack length will be solved iteratively for a given load. Once the crack length is established Equation 5 will be used to calculate the stress intensity. The compliance function ' $\mathrm{f}(\mathrm{a} / \mathrm{w})$ ' is given in

\section{Equation 5: Stress Intensity Solution for Compact Tension Specimen}

$$
K_{I}=\frac{P \cdot f\left(\frac{a}{w}\right)}{B \sqrt{W}}
$$

\section{Equation 6: Compliance Functions Solutions for Compact Tension Specimen}

$$
f\left(\frac{a}{w}\right)=\frac{2+\frac{a}{w}}{\left(1-\frac{a}{w}\right)^{\frac{3}{2}}}\left[0.886+4.64\left(\frac{a}{w}\right)-13.32\left(\frac{a}{w}\right)^{2}+14.72\left(\frac{a}{w}\right)^{3}-5.6\left(\frac{a}{w}\right)^{4}\right]
$$

The stress intensity will be calculated and ultimately the $\mathrm{K}_{\mathrm{ISCC}}$ will be reported.

\section{INITIAL RESULTS - TEST METHODS VALIDATION}

The J-R curves for E400 tested in the T-L and L-T orientation are shown in Figures 1 and 2 respectively with test conditions (temperature and nominal thickness) shown in the legend. [4] Interim fracture toughness properties were determined by segregating results from the $\mathrm{E} 400$ heat of steel (high carbon steel heat with composition similar to waste tank steel composition) into two sets: (1) T-L, low toughness orientation with flaws parallel to the rolling 
direction; and (2) L-T, high toughness orientation with flaws perpendicular to the rolling direction.

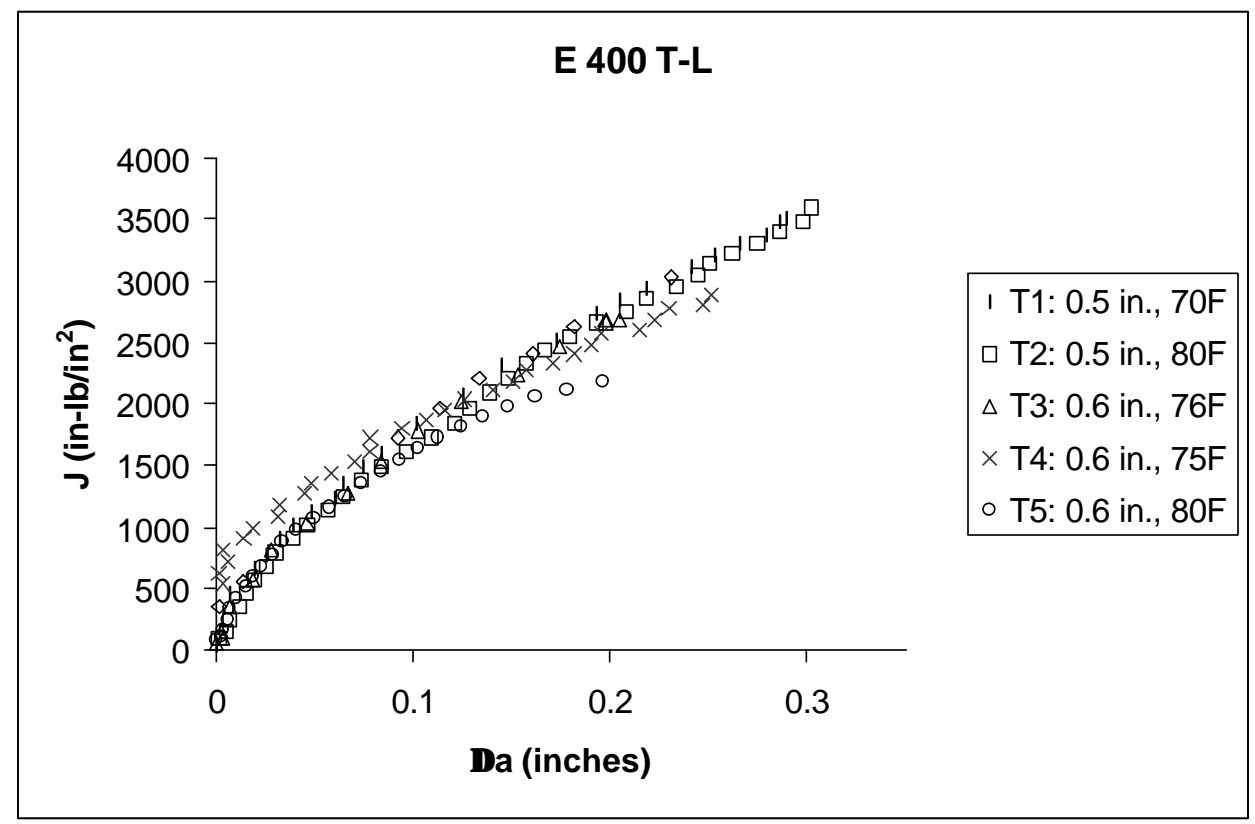

Figure 6: Heat E400, T-L Orientation J- $\Delta$ a Curves

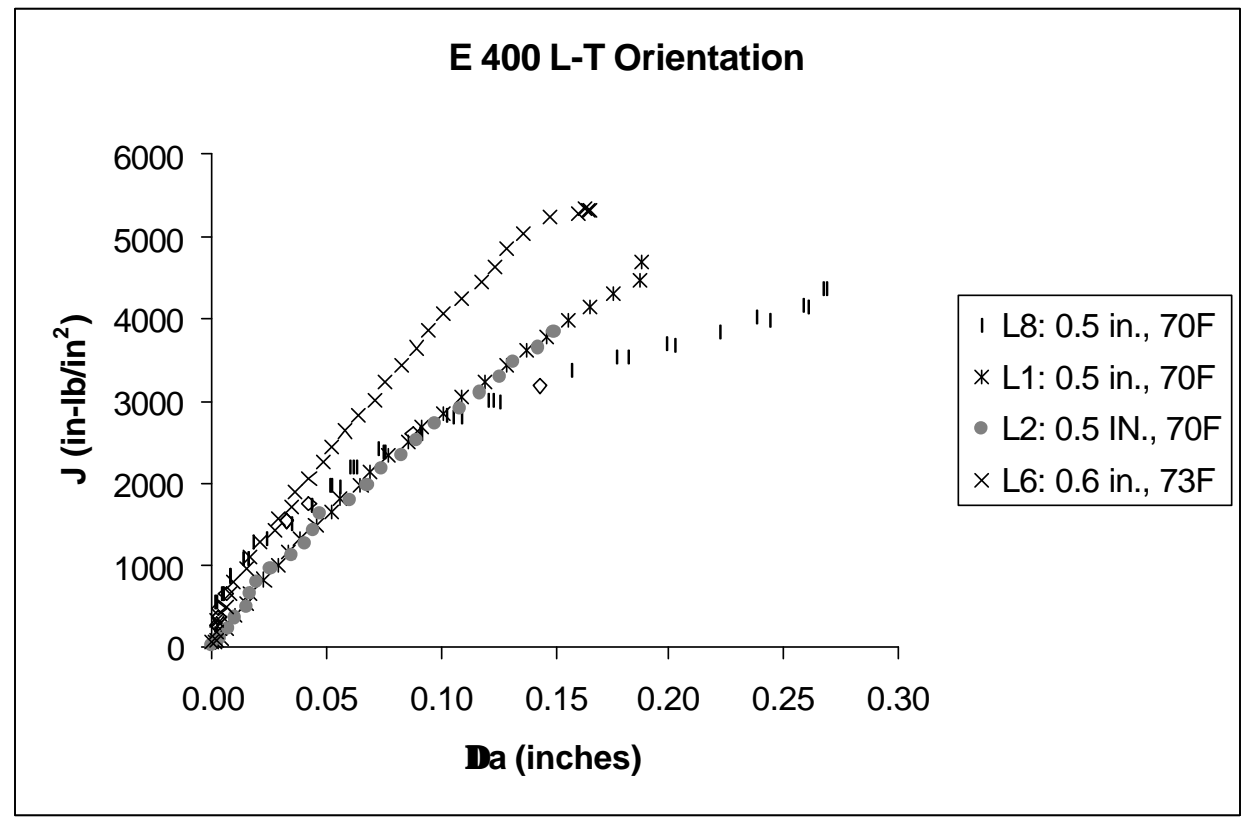

Figure 7: Heat E400, L-T Orientation J- $\Delta$ a Curves

The interim findings in comparing the toughness results from the tests are the following:

- Strong dependency on orientation with rolling direction (the "low toughness" orientation is with the crack aligned parallel to the rolling direction of the plate)

- Strong dependency on composition (lower toughness with increased carbon content) 
- Varied dependency on loading rate

The samples that were tested after heat tinting for accurate crack measurement were re-tested, and exhibited complete brittle fracture.

\section{CONCLUSIONS}

The current results have allowed for the general understanding of how certain variables affect the fracture energy at static loading rates. However, in order to complete the integration of these properties into flaw stability analyses for high level waste tanks, additional work is required. First, additional testing is required to complete a quantitative and predictive model of the impact of these variables on the fracture energy. This additional testing should also enable for the explanation of the sensitivity of the model to these variables as loading rate increases to dynamic rates. A statistically designed test matrix should be utilized to complete the matrix by which a predictive model of properties may be constructed. Second, additional microstructural analysis is required to develop a fundamental understanding of the role of microstructure on fracture energy and to determine more quantitative structure/property relationships. Finally, a phased approach to large-scale tests on actual tank materials will validate the application of the predictive property model. This approach will successfully ensure that technical basis for applying the A285 property database to flaw stability analyses in high level waste tanks.

It is expected that the impact from the dynamic strain aging phenomena will not have a significant adverse effect on material properties inputs used for structural analysis. However, the testing described here provide a confirmatory technical bases.

\section{ACKNOWLEDGEMENTS}

The authors of this report thank Dr. John J. Lewandowski and Chris Tuma of Case Western Reserve University for the testing of the fracture toughness specimens. 


\section{REFERENCES}

${ }^{1}$ Sedricks, A. J., Stress Corrosion Cracking Test Methods, National Association of Corrosion Engineering, Houston, TX, 1990, p. 53.

${ }^{2}$ Rolfe, S.T., Barsom, J. M., Fracture and Fatigue Control in Structures: Applications of Fracture Mechanics Prentice-Hall, Englewood Cliffs, NJ, 1977, pp. 292-311.

${ }^{3}$ Donovan, J. A. "Factors Controlling Nitrate Cracking of Mild Steel," Proceedings of Conference on Environmental Degradation of Engineering Materials, Blacksburg, VA, October 1977.

${ }^{4}$ McGannon, H. E., “The Making, Shaping and Treating of Steel,” United States Steel, $9^{\text {th }}$ ed., 1971.

${ }^{5}$ Chu, W. Y., Wang, Y. B., Qiao, L. J., "Interaction between blue brittleness and stress corrosion cracking," Letters to the Editor, Journal of Nuclear Materials, Vol. 280, 2000.

${ }^{6}$ Burns, K. W., Pickering, F. B., "Deformation and Fracture of Ferrite-Pearlite Structures,” Journal of Iron and Steel Institute, November 1964.

${ }^{7}$ Anderson, T. L., Fracture Mechanics, $2^{\text {nd }}$ Ed., CRC Press, 1995. 